\title{
Influências da temperatura de armazenamento e de extratores na determinação de glomalina em solos Paraibanos ${ }^{1}$
}

\author{
Influences of storage temperatures and extraction solutions on the determination of \\ glomalin in Paraiban soils
}

\author{
Carla da Silva Sousa ${ }^{2 *}$, Rômulo Simões Cezar Menezes ${ }^{3}$, Everardo Valadares de Sá Barretto Sampaio ${ }^{3}$ e \\ Francisco de Sousa Lima ${ }^{2}$
}

\begin{abstract}
Resumo - Fungos micorrízicos arbusculares (FMA) produzem glomalina, uma glicoproteína que contribui na formação de agregados estáveis, no seqüestro de metais pesais e como um reservatório de $\mathrm{C}$ e $\mathrm{N}$ nos solos. Solo, clima, espécie fúngica, vegetação, sistema de uso do solo e práticas de manejo agrícola influenciam na quantidade de glomalina produzida pelos FMA. Foram avaliadas a eficiência de extratores e o efeito da temperatura de armazenamento das amostras sobre a quantidade de glomalina extraída de um Neossolo Flúvico e de um Luvissolo, localizado na região semiárida Paraibana, Nordeste do Brasil. Os teores de glomalina foram quantificados logo após a coleta das amostras em campo e 15 meses após partes delas serem mantidas em temperatura ambiente $\left( \pm 25^{\circ} \mathrm{C}\right)$ ou em refrigerador $\left( \pm 4^{\circ} \mathrm{C}\right)$. Na quantificação foram testadas duas soluções extratoras: citrato de sódio e pirofosfato de sódio, (ambas a $20 \mathrm{mM}$; pH 7,0). As amostras armazenadas em refrigerador apresentaram até $47,6 \%$ mais glomalina que as mantidas em temperatura ambiente. Não foram observadas diferenças significativas entre as quantidades extraídas com citrato de sódio e com pirofosfato de sódio. Para uma quantificação mais precisa da glomalina, recomenda-se a refrigeração das amostras de solo após a coleta em campo.
\end{abstract}

Palavras-chave - Solos. Glomalina. Fungo.

\begin{abstract}
Arbuscular mycorrhizal fungi (AMF) produce glomalin, a glycoprotein that contributes to the formation of stable aggregates, to the sequestration of heavy metals and as a pool of $\mathrm{C}$ and $\mathrm{N}$ in soils. Soil, climate, fungi specie, vegetation type, land use system, and crop management practices influence the amount of glomalin deposited by the AMF. The efficiency of two extraction solutions and the effect of two storage temperature on the amount of glomalin were determined in samples of a Fluvic Neosol and a Luvisol, located in the semi-arid area of Paraiba state, Northeast Brazil. Glomalin contents were quantified soon after sampling and 15 months after storing part of the samples at room temperature $\left( \pm 25^{\circ} \mathrm{C}\right)$ or in a refrigerator $\left( \pm 4{ }^{\circ} \mathrm{C}\right)$. Quantification was tested with sodium citrate or with sodium pyrophosphate (both at $20 \mathrm{mM}, \mathrm{pH} 7.0$ ). The samples stored in the refrigerator had up to $47.6 \%$ more glomalin that the ones maintained at room temperature. There were no significant differences between the amounts extracted with sodium citrate or with sodium pyrophosphate. It is recommended to refrigerate the soil samples after field collection, to obtain a better quantification of glomalin.
\end{abstract}

Keywords - Soils. Glomalin. Fungi.

\footnotetext{
* Autor para correspondência

${ }^{1}$ Recebido para publicação em 17/11/2009; aprovado em 13/06/2011

Parte da Tese de Doutorado do primeiro autor apresentada ao Programa de Pós Graduação em Tecnologias Energéticas e Nucleares/ UFPE

${ }^{2}$ Centro de Ciências Agrárias, Ambientais e Biológicas/UFRB, Rua Rui Barbosa, Campus Universitário, Cruz das Almas-BA, Brasil, 44.380-000, cssagro@yahoo.com.br, fsousalima@yahoo.com.br

${ }^{3}$ Departamento de Energia Nuclear/UFPE, Av. Prof. Luiz Freire, 1000, Cidade Universitária, Recife-PE, Brasil, 50.741-110, rmenezes@ufpe.br, esampaio@ufpe.br
} 


\section{Introdução}

A glomalina é uma glicoproteína hidrofóbica, termoestável e recalcitrante produzida por fungos micorrízicos arbusculares (FMA). Em estudos de campo sobre indicadores da atividade dos FMA, a quantificação do teor de glomalina no solo apresenta-se como uma avaliação rápida, barata, objetiva e relativamente fácil de ser realizada em comparação às outras variáveis, como densidade de esporos, comprimento de hifas, colonização radicular e número mais provável de propágulos infectivos de FMA no solo (PURIN; RILLING, 2007).

Embora seja utilizado forte extrator e alta temperatura no processo de extração da glomalina das hifas e do solo, a estrutura desta glicoproteína não é afetada, o que demonstra que a molécula é muito estável (WRIGHT et al., 1996). Numerosos solubilizadores de proteínas incluindo detergentes, ácidos, bases, solventes e agentes caotrópicos não são eficientes em solubilizar glomalina do micélio fúngico (DRIVER et al., 2005). De forma semelhante, extratores quelantes como EDTA ou EDDHA, não tiveram sucesso em liberar a glomalina adsorvida aos minerais de argila (GONZÁLEZ-CHAVÉZ et al., 2004).

A solubilização de glomalina na hifa ou no solo é efetuada através do uso de citrato de sódio 20-50 mM, pH 7,0 ou 8,0, em elevada temperatura $\left(121^{\circ} \mathrm{C}\right)$ (WRIGHT; UPADHYAYA, 1996; WRIGHT et al., 1996). O citrato atua como um quelante do ferro associado à glomalina (WRIGHT; UPADHYAYA, 1998) e desta forma, auxilia a solubilização da molécula (WRIGHT et al., 2006). A glomalina pode também ser liberada de complexos organominerais por ação do sódio que dispersa óxidos de $\mathrm{Fe}$ e $\mathrm{Al}$ que atuam como ligantes entre a proteína e minerais de argila (CLAPP; HAYRES, 1999).

Além do extrator utilizado, a eficiência da extração da glomalina depende do $\mathrm{pH}$ da solução extratora e da temperatura durante o processo de extração. Possivelmente, características químicas e físicas dos solos, bem como, temperatura e período de armazenamento das amostras, podem influenciar na quantidade de glomalina extraída. Neste sentido, o presente trabalho teve como objetivo avaliar a eficiência do citrato de sódio e pirofosfato de sódio como extratores da glomalina, bem como o efeito da temperatura de armazenamento, ao longo de um período de 15 meses, sobre a quantidade dessa proteína extraída de amostras de dois tipos de solo da região semiárida paraibana.

\section{Material e métodos}

Amostras de um Neossolo Flúvico $\left(\mathrm{A}_{1}\right)$ e um Luvissolo $\left(\mathrm{A}_{2}\right)$, da região semiárida paraibana foram coletadas, de forma aleatória em caminho zig zag, na profundidade de $0-15 \mathrm{~cm}$. Após coletados, os solos foram secos ao ar, destorroados, homogeneizados e peneirados em peneira de $2 \mathrm{~mm}$. O A é um solo degradado de textura areia franca, que está, há muitos anos, sob cultivo agrícola, sem insumos, localizado no município de Taperoá, semiárido paraibano, que tem precipitação média anual de $558 \mathrm{~mm}$ e temperatura média anual de $26^{\circ} \mathrm{C}$. O $\mathrm{A}_{2}$ é um solo de textura franco argilo arenosa, que se encontra sob vegetação de caatinga, utilizado como pasto, localizado no município de Patos, semiárido paraibano, que tem precipitação média anual de $600 \mathrm{~mm}$ e temperatura média anual de $32,8^{\circ} \mathrm{C}$.

Foi realizada a caracterização química e física da camada de 0-15 cm dos solos (TAB. 1), de acordo com metodologias propostas pela Embrapa (1997): pH em $\mathrm{H}_{2} \mathrm{O}$ (solo: 2,5 água, v/v) por potenciometria; $\mathrm{Ca}^{+2}{\mathrm{e} \mathrm{Mg}^{+2}}^{+2}$ extraídos por $\mathrm{KCl}$ e determinados por absorção atômica; $\mathrm{P}$, $\mathrm{K}^{+}$e Na, extraídos com solução de Mehlich I e determinados por fotometria de chama $\left(\mathrm{K}^{+}\right.$e Na) e por colorimetria $(\mathrm{P})$; C orgânico (C.O.), determinado por oxidação úmida em dicromato de potássio; matéria orgânica (M.O.), estimada multiplicando-se o conteúdo de C orgânico por 1,724; e granulometria pelo método do densímetro.

Em subamostras dos dois solos, foi realizada também a quantificação inicial de glomalina, pelo método de Wright e Upadhyaya (1998), no qual 0,25 g de solo foram autoclavados por 30 minutos a $121^{\circ} \mathrm{C}$ com $2 \mathrm{~mL}$ de citrato de sódio (20 mM; pH 7,0), e em seguida centrifugados a $10.000 \mathrm{rpm}$, durante $5 \mathrm{~min}$. O sobrenadante foi coletado para quantificação do teor de glomalina $\left(\mathrm{mg} \mathrm{g}\right.$ de solo $\left.{ }^{-1}\right)$, pelo método de Bradford (1976), utilizando como padrão albumina bovina sérica.

Amostras dos dois solos foram transferidas para sacos plásticos e submetidas a duas condições de armazenamento, sendo parte acondicionada à temperatura ambiente $\left( \pm 25^{\circ} \mathrm{C}\right)$ e outra parte em refrigerador $\left( \pm 4^{\circ} \mathrm{C}\right)$, durante 15 meses. Após este período, foi quantificado o teor de glomalina nas amostras dos dois solos submetidos às duas condições de armazenamento, utilizando como soluções extratoras citrato de sódio e pirofosfato de sódio (ambas a $20 \mathrm{Mm}$ com pH ajustado para 7,0).

$\mathrm{O}$ ensaio foi conduzido em delineamento de blocos ao acaso, esquema fatorial $2 \times 2 \times 2$, sendo dois tipos de solo, duas temperaturas de armazenamento das amostras (ambiente e refrigerada) e dois extratores (citrato de sódio e pirofosfato de sódio), com quatro repetições. Os resultados obtidos foram submetidos à análise de variância e as médias comparadas através do teste de Tukey, ao nível de 0,05 de probabilidade, utilizando o programa estatístico SISVAR (FERREIRA, 2000). 
Tabela 1 - Caracterização química e física dos solos

\begin{tabular}{|c|c|c|c|c|c|c|c|c|c|c|c|}
\hline \multirow{2}{*}{ Solo* } & \multirow{2}{*}{$\frac{\mathrm{pH}}{\mathrm{H}_{2} \mathrm{O}}$} & \multirow{2}{*}{$\frac{\mathrm{P}}{\mathrm{mg} \mathrm{kg}^{-1}}$} & $\mathrm{~K}$ & $\mathrm{Na}$ & $\mathrm{Ca}$ & $\mathrm{Mg}$ & C.O. & M.O. & \multicolumn{3}{|c|}{ Granulometria $\left(\mathrm{g} \mathrm{kg}^{-1}\right)$} \\
\hline & & & \multicolumn{4}{|c|}{$\mathrm{cmol}_{\mathrm{c}} \mathrm{kg}^{-1}$} & \multicolumn{2}{|c|}{$\mathrm{g} \mathrm{kg}^{-1}$} & Areia & Argila & Silte \\
\hline $\mathrm{A}_{1}$ & 7,16 & 58,41 & 0,42 & 0,24 & 4,52 & 0,73 & 10,03 & 17,46 & 723 & 147 & 130 \\
\hline $\mathrm{A}_{2}$ & 6,08 & 4,21 & 0,23 & 0,11 & 3,91 & 1,17 & 13,63 & 23,72 & 638 & 269 & 93 \\
\hline
\end{tabular}

$* \mathrm{~A}_{1}=$ Neossolo Flúvico; $\mathrm{A}_{2}=$ Luvissolo

\section{Resultados e discussão}

Verificou-se que independente da temperatura de armazenamento das amostras e do extrator utilizado, o solo $A_{2}$ apresentou maiores teores de glomalina que o $A_{1}$ (TAB. 2). Maiores teores de glomalina em $A_{2}$ são possivelmente explicados pelo $\mathrm{pH}$ de 6,08. Alguns autores (HADDAD; SARKAR, 2003; RILLING et al., 2003) observaram correlação negativa entre concentrações de glomalina e pH do solo. Fungos tendem a predominar em solos ácidos, pois em solos alcalinos existe maior concorrência com bactérias e outros organismos (BRADY, 1990). Como a glomalina é produzida por FMA, é de se esperar que haja maior produção desta proteína em solos ácidos em virtude de maior atividade fúngica nestas condições (HADDAD; SARKAR, 2003).

Observa-se, ainda, que o solo $\mathrm{A}_{2}$ possui menor teor de $\mathrm{P}$ disponível $\left(4,21 \mathrm{mg} \mathrm{kg}^{-1}\right)$ do que o solo $\mathrm{A}_{1}$ $\left(58,21 \mathrm{mg} \mathrm{kg}^{-1}\right)$. Loverlock et al. (2004) verificaram que solos com altas concentrações de $\mathrm{P}$ apresentaram menores concentrações de glomalina. Em condições de maior disponibilidade de nutrientes, principalmente $\mathrm{N}$ e $\mathrm{P}$, sinais moleculares emitidos pela planta hospedeira são afetados, inibindo a associação micorrízica, e conseqüentemente, a produção de glomalina pelos FMA.

$\mathrm{O}$ solo $\mathrm{A}_{2}$ apresentou maior teor de $\mathrm{C}$ orgânico $\left(13,63 \mathrm{~g} \mathrm{~kg}^{-1}\right)$ do que o solo $\mathrm{A}_{1}\left(10,03 \mathrm{~g} \mathrm{~kg}^{-1}\right)$. O C orgânico é um dos indicadores mais consistentes da concentração de glomalina nos ecossistemas. Correlações positivas entre as frações de glomalina e o teor de carbono orgânico, têm sido registradas tanto em solos cultivados quanto não cultivados (BIRD et al., 2002; FRANZLUEBBERS, 2000; NICHOLS; WRIGHT, 2005; RILLING et al., 2003; WRIGHT et al., 1996).

Além dos fatores edáficos que favorecem a simbiose micorrízica, e conseqüentemente maior produção de glomalina pelos FMA, o solo $\mathrm{A}_{2}$ apresenta maior teor de argila $\left(269 \mathrm{~g} \mathrm{~kg}^{-1}\right)$ que o $\mathrm{A}_{1}\left(147 \mathrm{~g} \mathrm{~kg}^{-1}\right)$, que pode atuar na proteção da glomalina, reduzindo a ação de micro-organismos decompositores. A decomposição da glomalina pode ser influenciada pelo conteúdo de argila, uma vez que estes minerais promovem proteção física no interior dos agregados (NICHOLS; WRIGHT, 2005), ou ainda pelo grau com que a molécula encontra-se ligada às partículas do solo (TRESENDER; TUNER, 2007).

Tabela 2 - Quantificação de glomalina $\left(\mathrm{mg} \mathrm{g} \mathrm{solo}^{-1}\right)$ em dois solos do semi-árido paraibano submetidos a duas temperaturas de armazenamento durante 15 meses, utilizando citrato de sódio e pirofosfato de sódio como extratores

\begin{tabular}{|c|c|c|c|c|}
\hline \multirow{4}{*}{ Solo* } & \multicolumn{4}{|c|}{ Extrator } \\
\hline & \multicolumn{2}{|c|}{ Citrato de sódio } & \multicolumn{2}{|c|}{ Pirofosfato de sódio } \\
\hline & \multicolumn{4}{|c|}{---------------------------Temperatura de armazenamento das amostras---------------------------- } \\
\hline & A & $\mathrm{R}$ & A & $\mathrm{R}$ \\
\hline $\mathrm{A}_{1}$ & $0,63 \mathrm{bB} \alpha \pm 0,08$ & $0,93 \mathrm{bA} \alpha \pm 0,08$ & $0,74 \mathrm{bA} \alpha \pm 0,05$ & $0,78 \mathrm{bA} \alpha \pm 0,07$ \\
\hline $\mathrm{A}_{2}$ & $0,97 \mathrm{aB} \alpha \pm 0,06$ & $1,37 \mathrm{aA} \alpha \pm 0,28$ & $0,99 \mathrm{aB} \alpha \pm 0,06$ & $1,37 \mathrm{aA} \alpha \pm 0,19$ \\
\hline $\mathrm{CV}(\%)$ & \multicolumn{4}{|c|}{14,40} \\
\hline
\end{tabular}


Após 15 meses de armazenamento em temperatura refrigerada $\left(4{ }^{\circ} \mathrm{C}\right)$, utilizando citrato de sódio como solução extratora, verificou-se que amostras dos solos $\mathrm{A}_{1}$ e $\mathrm{A}_{2}$ apresentaram maiores teores de glomalina (47,6 e $41,2 \%$, respectivamente) do que as amostras destes solos armazenadas em temperatura ambiente $\left(25^{\circ} \mathrm{C}\right)$. Não houve diferença significativa entre a quantidade de glomalina nas amostras armazenadas em temperatura ambiente e refrigerada do solo $\mathrm{A}_{1}$, quando utilizado o extrator pirofosfato de sódio. Contudo, amostras do $\mathrm{A}_{2}$ apresentaram maior teor de glomalina $(38,4 \%)$ quando armazenadas em temperatura refrigerada. Rilling et al. (2003) demonstraram que $57 \%$ da glomalina permaneceu após 413 dias de incubação do solo a $25^{\circ} \mathrm{C}$, em laboratório, indicando que certa quantidade desta proteína pode ser uma fração recalcitrante do C do solo. Steinberg e Rilling (2003) observaram que após 150 dias de incubação do solo a $18{ }^{\circ} \mathrm{C}$, a concentração de glomalina diminuiu em $25 \%$.

Embora a glomalina seja uma biomolécula relativamente estável (WRIGHT; UPADHYAYA, 1998), o armazenamento das amostras de solo em temperatura ambiente pode ter favorecido a atividade microbiana, com degradação de hifas e esporos (DRIVER et al., 2005), e utilização da glomalina como fonte de substrato para seu crescimento (RILLING et al., 2003).

Não houve efeito significativo da temperatura de armazenamento das amostras sobre a quantidade de glomalina extraída dos solos $A_{1}$ e $A_{2}$ pelos extratores citrato de sódio e pirofosfato de sódio. Tendo em vista que o citrato de sódio é um extrator padrão utilizado para extração da glomalina de solos (WRIGHT; UPADHYAYA, 1998), os resultados demonstraram que o pirofosfato de sódio surge como uma opção a mais para ser utilizada na extração desta proteína. Wright et al. (2006) verificaram inclusive, que pirofosfato de sódio foi mais eficiente do que borato de sódio e citrato de sódio (todos na concentração $100 \mathrm{mM}$; pH 9,0) na extração de glomalina, em sete solos.

\section{Conclusões}

1. Recomenda-se a refrigeração das amostras de solo a $4{ }^{\circ} \mathrm{C}$ após a coleta para quantificação mais precisa da glomalina, uma vez, que quando armazenadas à temperatura ambiente $\left(25^{\circ} \mathrm{C}\right)$, apresentaram menor teor desta proteína;

2. O pirofosfato de sódio foi tão eficiente quanto o citrato de sódio na extração de glomalina nos dois solos.

\section{Agradecimento}

O presente trabalho foi parcialmente financiado com recursos do IAI (CRN2-014); do CNPq (Edital MCT/ CNPq/MDA/SAF/MDS/SESAN 36/2007- Agricultura Familiar - Processo 551731/07-9); e do Edital Facepe PPP 2006 (Processo APQ-0633-5.01/06). Os autores também agradecem ao CNPq pela concessão de bolsa de doutorado e de produtividade de pesquisa.

\section{Referências}

BIRD, S. B. et al. Spatial heterogeneity of aggregate stability and soil carbon in semi-arid rangeland. Environmental Pollution, v. 116, n.03, p. 445-455, 2002.

BRADFORD, M. M. A rapid and sensive method for the quantification of microgram quantities of protein utilizing the principle of protein-dye binding. Analytical Biochemistry, v. 72, p. $248-254,1976$

BRADY, N. C. The nature and properties of soils. 10. ed. New York: Macmillan Publishing, 1990. p. 227-230.

CLAPP, C. E.; HAYRES, M. H. B. Characterization of humic substances isolated from clay and silt sized fractions of a corn residue-amended agricultural soil. Soil Science, v. 164, n. 12, p. 899-913, 1999.

DRIVER, J. D.; HOLBEN, W. E.; RILLING, M .C. Characterization of glomalin as a hyphal wall component of arbuscular mycorrhizal fungi. Soil Biology \& Biochemistry, v. 37, n. 01, p. 101-106, 2005.

EMPRESA BRASILEIRA DE PESQUISA AGROPECUARIA - (EMBRAPA). Centro Nacional de Pesquisa de Solos. Manual de Métodos de Análise do Solo. 2. ed. Rio de Janeiro: EmbrapaCNPS, 1997. 212 p.

FERREIRA, D. F. Análises estatísticas por meio do Sisvar para Windows versão 4.0. In: REUNIÃO ANUAL DA REGIÃO BRASILEIRA DA SOCIEDADE INTERNACIONAL DE BIOMETRIA, 45., 2000, São Carlos. Anais... São Carlos: UFSCar, 2000. p. 255-258.

FRANZLUEBBERS, A. J.; WRIGHT, S. F.; STUEDEMANN, J. A. Soil aggregation and glomalin under pastures in the southern Piedmont USA. Soil Science Society of America Journal, v. 64, p. 1018-1026, 2000.

GONZÁLEZ-CHAVÉZ, M. C. et al. The role of glomalin, a protein produced by arbuscular mycorrhizal fungi, in sequestering potentially toxic elements. Environmental Pollution, v. 130, n. 03, p. 317-323, 2004.

HADDAD, M. J.; SARKAR, D. Glomalin, a newly discovered component of soil organic matter: Part II - Relationship with soil properties. Environmental Geosciences, v. 10, n. 03, p. 99-106, 2003. 
LOVERLOCK, C. E. et al. Soil stocks of glomalin produced by arbuscular mycorrhizal fungal across a tropical rain forest landscape. Journal of Ecology, v. 92, n. 02, p. 278-287, 2004.

NICHOLS, K. A.; WRIGHT, S. F. Comparison of glomalin and humic acid in eight native US soils. Soil Science, v. 170, n. 12, p. 985-997, 2005.

PURIN, S.; RILLING, M. C. The arbuscular mycorrhizal fungal protein glomalina: limitations, progress, and a new hypothesis for its function. Pedobiologia, v. 51, p. 123-130, 2007.

RILLING, M. C. et al. Glomalin, an arbuscular-mycorrhizal fungal soil protein, responds to soil-use change. Plant and Soil, v. 253, p. 293-299, 2003.

STEINBERG, P. D.; RILLIG, M. C. Differential decomposition of arbuscular mycorrhizal fungal hyphae and glomalin. Soil Biology \& Biochemistry, v. 35, n. 01, p. 191-194, 2003.
TRESEDER, K. K.; TURNER, K. M. Glomalin in ecosystems. Soil Science Society of America Journal, v. 71, n. 04, p. 1257-1266, 2007.

WRIGHT, S. F.; UPADHYAYA, A. Extraction of an abundant and unusual protein from soil and comparison with hyphal protein of arbuscular mycorrhizal fungi. Soil Science, v. 161, n. 09, p. 575-586, 1996.

WRIGHT, S. F. et al. Time-course study and partial characterization of a protein on hyphae of arbuscular mycorrhizal fungi during active colonization of roots. Plant and Soil, v. 181, n. 02 , p. $193-203,1996$

WRIGHT, S. F.; UPADHYAYA, A. A survey of soils for aggregate stability and glomalin, a glicoprotein produced by hyphae of arbuscular mycorrhizal fungi. Plant and Soil, v. 198, p. 97-107. 1998.

WRIGHT, S.F.; NICHOLS, K. A.; SCHMIDT, W.F. Comparison of efficiency of three extractants to solubilize glomalin on hyphae and in soil. Chemosphere, v. 64, p. 1219-1224. 2006. 